J Res Dentomaxillofac Sci

JRDMMS Journal of Research in Dental and Maxillofacial Sciences

\title{
Basal Cell Adenoma of the Parotid Gland: A Case Report and Review of the Literature
}

\author{
Tootoonchian A ${ }^{1}$, Sezavar $\mathbf{M}^{1}$, Kahali Asl $\mathbf{R}^{1}$, Nematollahi $Z^{2}$ \\ 1-Assistant Professor, Oral and Maxillofacial Surgery Dept, Dental Branch of Tehran, Islamic Azad University, Buali Hospital, Tehran, Iran. \\ 2- Member of Cranio maxillofacial Research center, Islamic Azad Dental University, Tehran, Iran.
}

\begin{tabular}{|c|c|}
\hline ARTICLE INFO & ABSTRACT \\
\hline & $\begin{array}{l}\text { Salivary gland tumors are among the pathologies in the head and neck that may be } \\
\text { challenging in diagnosis and treatment. Most benign tumors occur in the parotid }\end{array}$ \\
\hline $\begin{array}{l}\text { Article History } \\
\text { Received: June } 2015 \\
\text { Accepted: August } 2015 \\
\text { ePublished: Junuary } 2016\end{array}$ & $\begin{array}{l}\text { gland. Pleomorphic Adenoma is the most common type. Basal Cell Adenoma is a } \\
\text { subtype of the Monomorphic Adenoma with rare occurrence. Proper diagnosis and } \\
\text { clinical evaluation by the use of radiography can lead the physician to the best treat- } \\
\text { ment plan for this neoplasia. Many surgical treatment modalities have been described }\end{array}$ \\
\hline $\begin{array}{l}\text { Keywords: } \\
\text { Basal cell adenoma } \\
\text { Salivary gland neoplasms } \\
\text { Parotid neoplasms }\end{array}$ & $\begin{array}{l}\text { in the literature ranging from total parotidectomy to dissection of the tumoral area } \\
\text { alone. Extensive surgery will lead to malfunction and unacceptable esthetics due to } \\
\text { resection of the parotid gland. One of the best approaches for treating the encapsulated } \\
\text { and well-circumscribed pathologies is extra-capsular dissection without invading the } \\
\text { major salivary gland. A rare case of Basal Cell Adenoma of the parotid gland in a } \\
\text { 47-year-old female will be discussed. }\end{array}$ \\
\hline
\end{tabular}

Please cite this paper as:

Tootoonchian A, Sezavar M, Kahali Asl R, Nematollahi Z. Basal Cell Adenoma of the Parotid Gland: A Case Report and Review of the Literature. J Res Dentomaxillofac Sci. 2016;1(1):17-21.

\section{Introduction:}

Monomorphic Adenoma (MA) is a pathologic condition related to the salivary glands and differs from the Pleomorphic Adenoma (PA) in clinical behavior and histologic appearance. Basal Cell Adenoma (BCA) is one of the subtypes of the MA, which was first described by Kleinsasser and Klein in 1967. ${ }^{(1)}$ The BCA accounts for about $2 \%$ of all the salivary tumors ${ }^{(2)}$ and about $54 \%$ of all the MAs. ${ }^{(3)}$ It is considered as a low-grade malignant tumor with a high recurrence rate and good prognosis. The most fre- quently involved location is the parotid gland followed by upper and lower lip, palate, buccal mucosa and even nasal septum. . $^{(3,4)} 80 \%$ of the BCAs arise in major salivary glands, and about $70 \%$ occur in the parotid gland during the 5-7th decades of life with a 2:1 female-to-male predominance. ${ }^{(1,4-6)}$ The most common clinical presentation is a painless swelling, detected during self-body evaluation by the patient. The differential diagnosis includes the PA and Adenoid Cystic Carcinoma (ACC), which should 
be carefully considered because of the differences in prognosis and treatment plans.

BCA of the salivary gland is an uncommon subtype of the MA with only few proven cases which have been previously reported. A rare case of BCA of the parotid gland will be discussed with review of the literature.

\section{Case presentation}

In April 2012, a 47-year-old white female was admitted to the oral and maxillofacial ward of the Buali Hospital in Tehran, Iran, complaining of an abnormal painless swelling which had appeared approximately a year ago and had become progressively enlarged during the last 3 months. (Figure 1) The patient had no systemic disorders. Extraoral evaluation revealed a $3 \times 3 \mathrm{~cm}$ painless mobile non-fluctuant mass below the right earlobe. The skin had a normal appearance without any heat or redness. All facial movements in the right side were intact and symmetric. Examination of the parotid duct performed by milking the parotid gland while examining the Stenson's duct intraorally, showed normal secretory function of the gland. No signs or symptoms of infection were present.

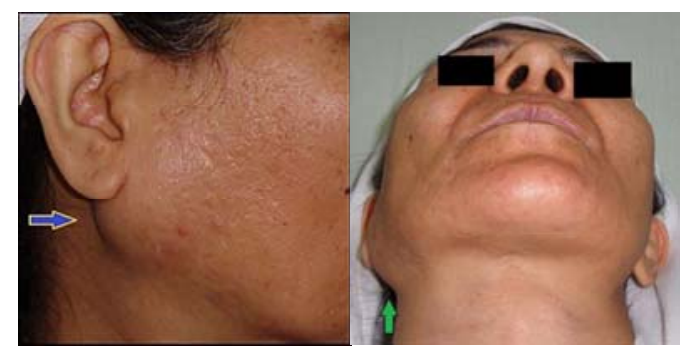

Figure 1- A 47-year-old patient with a painless swelling below the right earlobe.

CT scan images showed a solid unilateral mass in the superficial lobe of the parotid gland (Figure 2), which seemed to be encapsulated without any connection to the parenchyma of the gland.
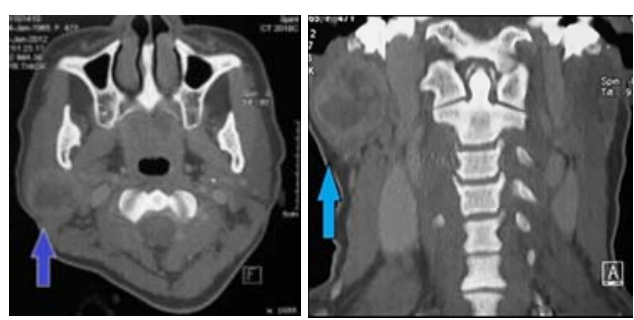

Figure 2- CT scan evaluation of the patient revealed a solid mass in the superficial part of the parotid gland. Left: Axial view, Right: Coronal view.

The patient was afraid of having cancer and assumed that fine needle aspiration (FNA) biopsy would spread the tumor in her body; therefore, she refused consent for the procedure and insisted on complete excision of the lesion. Radiologic and clinical evaluations revealed that the tumor was distinct from the parenchyma of the parotid gland and was attached to the gland by a small pedicle. (Figure 3)
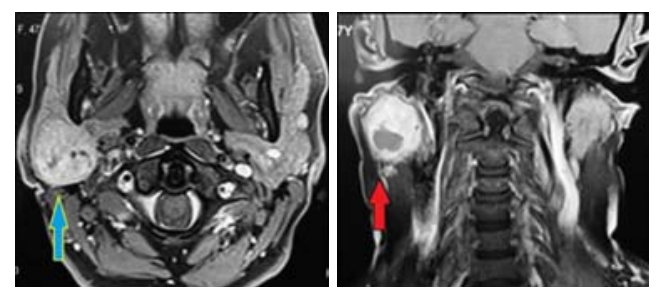

Figure 3- MRI evaluation revealed that the tumor is separate from the parotid gland. Left: Axial view, Right: Coronal view.

The patient was transferred to the operating room for incisional / excisional biopsy according to the intraoperative findings. A curvilinear skin flap was raised in a plane immediately above the parotid fascia to the $1 \mathrm{~cm}$ periphery of the tumor. Since the intraoperative findings had shown a capsulated tumor with distinct periphery, the surgeon decided to completely excise the tumor. Blunt dissection around the capsular area of the tumor was carried out with Metzenbaum scissors and finger dissection. (Figure 4) The tumor capsule remained intact. 


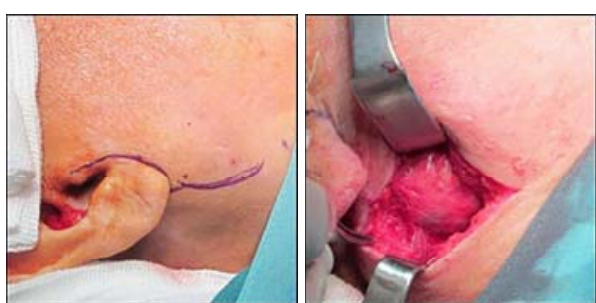

Figure 4- A curvilinear skin flap was raised in a plane immediately above the parotid fascia to the periphery of the tumor.

The tumor was completely excised, and the small vessel leading to the tumor was ligated with a 3-0 silk tie suture. The parotid capsule remained intact. (Figure 5) Two-layer closure was performed and pressure bandage dressing was applied immediately after the operation.
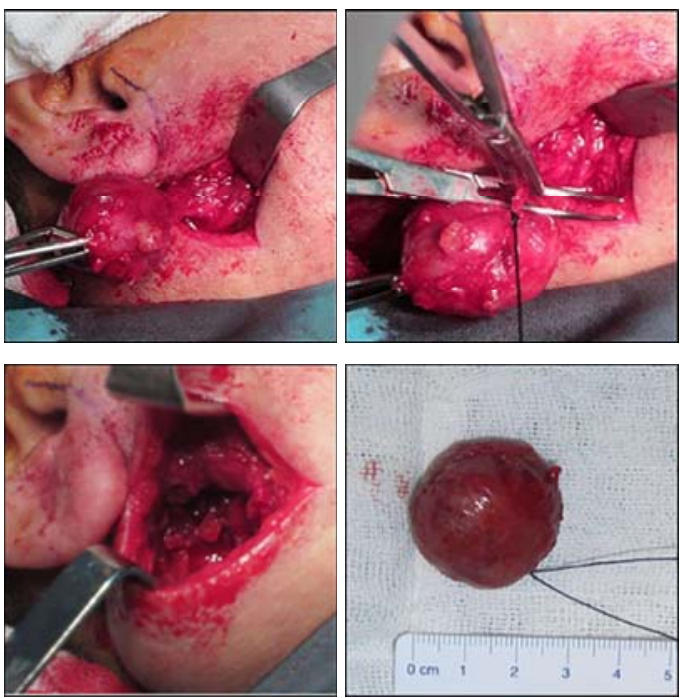

Figure 5- The tumor was completely excised, and the small vessel leading to the tumor was .ligated with a 3-0 silk tie suture

The specimen was transferred to laboratory for histopathologic evaluations. The pathologist described the specimen as a $2.5 \times 2.5 \times 2$ $\mathrm{cm}$ encapsulated well-defined creamy-gray mass with elastic and rubbery consistency. Microscopic evaluation revealed an encapsulated benign neoplasm composed of relatively uniform epithelial cells arranged in solid nests with peripheral palisading of the nuclei surrounded by thick hyaline bands, tubules and trabeculae. (Figure 6) No significant mitotic activity was reported. The final diagnosis was Basal Cell Adenoma of the parotid gland and the results were negative for malignancy.

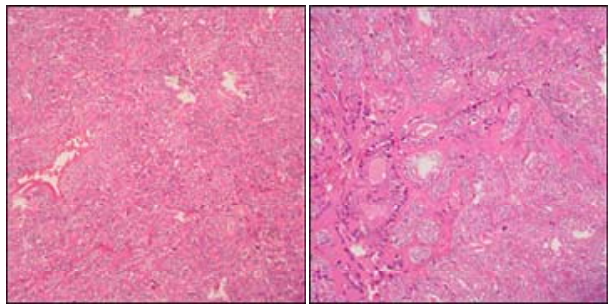

Figure 6- Microscopic evaluation revealed a benign neoplasm composed of relatively uniform epithelial cells arranged in solid nests with peripheral palisading of the nuclei surrounded by hyaline bands, tubules and trabeculae.

\section{Discussion:}

The average incidence per 100,000 individuals is 4.7 for the benign and 0.9 for the malignant variants of salivary gland tumors. ${ }^{(7)}$ Ansari studied 130 cases in Iran and stated that the most common site for benign minor salivary gland tumors is the anterior floor of the oral cavity, and the most common site for malignant types is the palate. He encountered MA cases $(2 \%)$ in his study, which were all arising in the parotid gland (Canalicular adenoma or BCA). ${ }^{(7)}$

The BCA has solid, trabecular, tubular and membranous subtypes. The most common subtype is solid. This slow-growing encapsulated tumor does not exceed more than $3 \mathrm{~cm}$ in diameter, and is firm, mobile and usually without any signs. The most accurate diagnosis can usually be made through biopsy. Some researchers have favored FNA biopsy. ${ }^{(3)}$ Perhaps, the BCA arises from the epithelial cells of the terminal duct. ${ }^{(1)}$ Mesenchymal component or chondromyxoid stroma is absent (unlike PA). ${ }^{(4,8)}$ There is an association between the occurrence of the BCA and cutaneous cylindroma, trichoepithelioma or eccrine spiradenoma of the scalp. ${ }^{(1,4)}$ Also, there has been a report regarding the synchronous ipsilateral occurrence of sebaceous lymphadenoma and membranous BCA of the parotid gland in a 46-year-old male. (9) Unlike BCA, an infiltrative growth, more than 4 mitotic count per $10 \mathrm{HDP}$ and Ki 67-staining 
of $5 \%$ of the cells are detected in the Basal Cell Carcinoma (BCC). Whirlpool of epithelial cells, dark external cells in a stockade fashion and thick basal membrane are observed in the ACCs. ${ }^{(4)}$ The Basal Cell Adenoid Carcinoma (BCAC) differs from the $\mathrm{BCA}$ in having an invasive behavior, higher mitotic activity and neural and vascular invasion. Malignant transformations to $\mathrm{BCAC}$ are rare but have been reported in $4.3 \%$ of the BCAs (Nagao et al, 1997). The membranous subtype which accounts for $25 \%$ to $37 \%$ of all the BCAs, is hereditary and recurrent, because of its multifocal nature which impairs complete removal by surgery. ${ }^{(1,6,10)}$ In immunohistochemical study (IHC), immunoreactivity to S-100 protein, Smooth Muscle Actin (SMA) and Vimentin can be confirmed in most of the BCAs. ${ }^{(10)}$

In European reports, most of the salivary gland tumors were superficial and all of them were unilateral. ${ }^{(5)}$ Less than 10 bilateral cases have been reported in a literature review by Junquera et al. ${ }^{(6)}$ The BCA has sharp margins, which means that it is distinct from the parenchyma of the parotid gland. Based on MRI, the main differential diagnoses for the BCA are Warthin's tumor, PA and BCAC. ${ }^{(11)}$

On T2-weighted MRI, the signal intensity is higher than that of muscle, whereas on T1-weighted sequences, the tumor is heterogeneously isointense to muscle. ${ }^{(12)}$ Dynamic CT findings are important in identifying the benign and malignant parotid tumors. Intensity enhancement has been shown in the early phases of the BCAs, which decreases gradually during the advanced phases (similar to the Warthin's tumor). Unlike BCA, enhancements are visible in CT scans of delayed phases of the PA and malignant tumors. (11) Reports have shown that the Hounsfield unit $(\mathrm{HU})$ in the BCA shows higher numeric values in comparison with the PA. The BCA shows the average of 46.8 to $91.43 \mathrm{HU}$ in unenhanced and contrast enhanced CT, respectively, while the PA has a range of 34.35 to $66.06 \mathrm{HU}$. A significant difference exists in the mean CT attenuation of the BCA and PA on unenhanced and contrast-enhanced images. Strong enhancement after contrast injection and hemorrhage in the BCA can be attributed to the vascular architecture. ${ }^{(8)}$ Chiu et al have reported 2 cases with capsular invasion without any positive CT findings. ${ }^{(8)}$
More than $93 \%$ of benign cases can be identified with clinical examination alone. The most important assessment is to see whether the skin flap elevates with palpation and to check its mobility. (13) Three treatment modalities have been introduced for the BCA: superficial parotidectomy, total parotidectomy, and partial parotidectomy or extra-capsular dissection. Some complications may occur after parotidectomy due to the injury of the seventh Cranial Nerve (CN VII=facial nerve). Other disadvantages include sunken defect due to loss of soft tissue volume and Frey's syndrome (10\% after superficial and 30\% after total parotidectomy).

Extra-capsular dissection is performed by removing the tumor-bearing area of the parotid parenchyma and preserving the rest of the gland. Orabona et al in 2013 stated that extra-capsular dissection does not lead to increased recurrence of the tumor and results in low morbidities. ${ }^{(14)}$ The advantages include minimal manipulation of the CN VII, eliminating the risk of Frey's syndrome, and low incidence of tumor spillage. Parotidectomy with minimal risk of CN VII injury can be performed later if indicated. ${ }^{(13-15)}$ No recurrences have been reported during 10 years of follow-up. (14) Extra-capsular dissection is indicated in case of a mobile benign superficial mass in the lateral lobe of the parotid gland. Parotidectomy is the treatment of choice when the diameter of the tumor exceeds $3 \mathrm{~cm}$ or when it is located parapharyngeally or in the deep portion of the gland. Maintaining the retraction of the elevated flap is the key to a successful extra-capsular dissection. (13,14) High doses of hypotensive anesthesia are not required since the surgeon is responsible for hemostasis not the anesthesiologist. ${ }^{(13)}$

\section{Conclusion:}

Extra-capsular dissection of the BCA is a proper alternative surgical method which can substitute superficial or total parotidectomy in cases of superficially-located small mobile tumors with an apparent intact capsule.

\section{Acknowledgments:}

The authors would like to thank the Dental research center of Tehran university of medical sciences and The AFM center of Iran universi- 
ty of science and Technology for the laboratory work.

\section{Conflict of interests:}

Authors report no conflict of interest related to this study.

\section{References:}

1.Esteves AR, Dib LL, de Carvalho LV. Basal Cell Adenoma: A Case Report. J Oral Maxillofac Surg 1997;55(11):1323-5.

2.Ogawa I, Nikai H, Takata T, Miyauchi M, Ito H, Ijuhin $\mathrm{N}$. The cellular composition of basal cell adenoma of parotid gland: An Immunohistochemical analysis. Oral Surg Oral Med Oral Pathol1990;70(5):619-26.

3.González-García R1, Nam-Cha SH, Muñoz-Guerra MF, Gamallo-Amat C. Basal cell adenoma of the parotid gland. Case report and review of the literature. Med Oral Patol Oral Cir Bucal 2006;11(2):E206-9

4.Chakravarthi S, Rao V.T, Prasad L.K, Kalyan, Kattimani V.S. Basal Cell Adenoma - A Rare Presentation of Parotid Swelling - A Case Report and Review of The Literature. Jr.of Orofac. Scie. 2009;1(2):13-16.

5.Chawla AJ, Tan TY, Tan GJ. Basal cell adenoma of parotid gland: CT scan features Eur J Radiol 2006;58(2):260-5.

6.Junquera L, Gallego L, de Vicente JC, Fresno MF. Bilateral parotid basal cell adenoma: an unusual case report and review of the literature. J Oral Maxillofac Surg 2010;68(1):179-82.

7.Ansari MH. Salivary gland tumors in an Iranian population: a retrospective study of 130 cases. J Oral Maxillofac Surg 2007;65(11):2187-94.

8.Chiu NC, Wu HM, Chou YH, Li WY, Chiou YY, Guo WY, Chang CY. Basal cell adenoma versus pleomorphic adenoma of the parotid gland: CT findings. AJR Am J Roentgenol 2007;189(5):254-61.

9.Scheller EL, Pritchett CV, Shukla A, Pepper JP, Marentette LJ, McHugh JB. Synchronous ipsilateral sebaceous lymphadenoma and membranous basal cell adenoma of the parotid. Oral Surg Oral Med Oral Pathol Oral Radiol 2013;115(4):e41-6.

10.Mărgăritescu C, Mercuţ V, Mogoantă L, Florescu M, Simionescu C, Cionca L, Manea M. Salivary gland Basal cell adenomas--immunohistochemical evaluation of four cases and review of the literature. Rom J Morphol Embryol. 2005;46(1):29-40.

11.Yerli H, Teksam M, Aydin E, Coskun M, Ozdemir $\mathrm{H}$, Agildere AM. Basal cell adenoma of the parotid gland:dynamic CT and MRI findings . Br J Radiol 2005;78(931);642-5.

12.Nakabayashi M, Shomori K, Kiya S, Shiomi T, Nosaka K, Ito H. Tubular-Trabecular Type Basal Cell Adenoma of the Parotid Gland: A Patient Report. Yo- nago Acta med 2010;53(3):65-9.

13.George KS, McGurk M. Extracapsular dissection-minimal resection for benign parotid tumours. $\mathrm{Br} \mathrm{J}$ Oral Maxillofac Surg 2011;49(6):451-4.

14.Dell>Aversana Orabona $\mathrm{G}$, Bonavolontà $\mathrm{P}$, Iaconetta G, Forte R, Califano L. Surgical management of benign tumors of the parotid gland: extracapsular dissection versus superficial parotidectomy--our experience in 232 cases. J Oral Maxillofac Surg 2013;71(2):4103.

15.Klintworth N, Zenk J, Koch M, Iro H. Postoperative complications after extracapsular dissection of benign parotid lesions with particular reference to facial nerve function. Laryngoscope 2010;120(3):484-90. 